\title{
Research on Prevention of Ship Collisions with Oil Rigs
}

\author{
Zhang Pengfei ${ }^{1}$, Zhao Minghua ${ }^{1}$, Sriram Rajagopal ${ }^{2}$ and Fotios Retouniotis ${ }^{1}$ \\ 1. School of Maritime Science and Engineering, Southampton Solent University, SO140YN, UK \\ 2. Global Maritime Education \& Training Association, Haryana 122001, India
}

\begin{abstract}
The consequences of ship collisions with an oil rig, offshore installation or platform can be far more expensive in relation to safety, environment and costs of damage. The damage due to a single incident of an Oil Rig Collision can be catastrophic due to the number of people on board and the added risk of explosion. However, the existing rules and regulations of collisions prevention are insufficient. The purpose of this article is to critically evaluate the risk of ships collisions with offshore platforms and installations and therefore propose an international regulation for the preventions of this type of collisions.
\end{abstract}

Key words: Collision, oil rigs, ships, prevention.

\section{Introduction}

The International Regulations for Preventing Collisions at Sea (1972) (COLREGs) have played a significant role in ensuring a safe navigation and operation of ships. However, offshore drilling platforms are excluded out of the system. With more and more offshore drilling platforms rising at sea, it has been a most urgent task to give a serious consideration on how to avoid collisions between offshore drilling platforms and ships [1].

Accurate quantification of risks for ship collisions with oil rigs (S/O Collisions) has been a goal of the petroleum industry for many years; however, technological advances in collision avoidance systems have not been reflected in current models. Although, a major collision between passing merchant vessels and offshore platforms has not yet been experienced, the accident potential is significant. With every new hydrocarbon discovery, the risk of ship-platform collision increases. The platform operator has little influence over the collision potential beyond the selection of the platform's location.

Corresponding author: Zhang Pengfei, Dr., master mariner and maritime lawyer, research fields: nautical science, maritime law, shipping business.

\section{Ship and Oil Rig Collision Accidents}

The consequences of any collisions with an oil rig, off shore installation or platform can be far more expensive in relation to safety, environment and costs of damage. As Fig. 1 shows, the damage due to a single incident of an ORC (Oil Rig Collision) can be catastrophic. This is because of two reasons: firstly, the increased risk of the live personnel due to the number of people on board; secondly, because of the added risk of explosion due to the highly flammable and explosive gases involved and the resultant costs and losses due to lost production.

Platforms are designed to withstand smaller impacts from supply vessels, but passing vessels generally travel at higher speeds and consequently the displacement will likely to be greater than that of an attending vessel. Even at modest speeds, the inherent energy transfer to the platform can easily cause deformation of structural members and possibly a total failure [2]. Although only a small fraction of collisions recorded in the UKCS Ship/Platform Collision Incident Database involved passing vessels, the consequences of this type of accident are significant.

Accurately modelling vessel-to-platform collision risk is a problem which has challenged the industry for over 20 years [3]. There are numerous social, technical, and environmental variables which influence the highly 


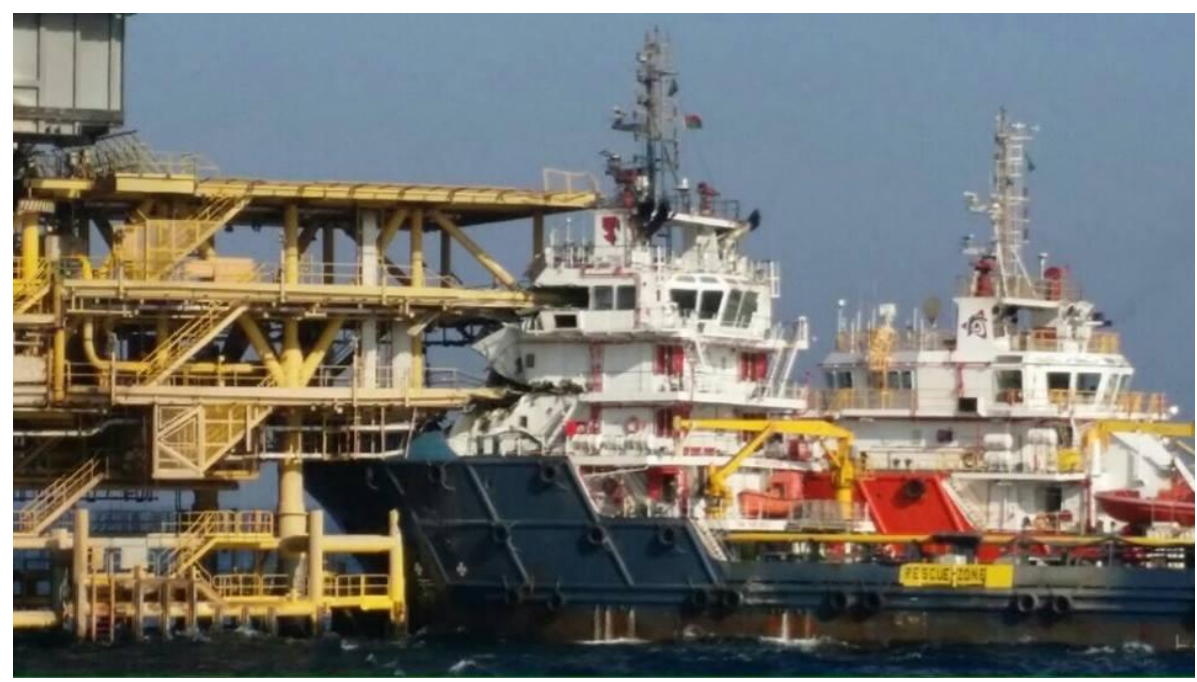

Fig. 1 Ship collision with oil rig.

Table 1 List of prominent oil rig disasters due to collisions.

\begin{tabular}{|c|c|c|}
\hline Name & Year Location & Damage and consequences \\
\hline $\begin{array}{l}\text { Mumbai high north incident-collision with } \\
\text { the multipurpose support vessel MV Samudra } \\
\text { Suraksha }\end{array}$ & $2005 \begin{array}{l}\text { Arabian sea (off Indian } \\
\text { coast) }\end{array}$ & $\begin{array}{l}\text { Numerous fires and explosions, } 22 \text { lives lost, MHN } \\
\text { oil platform and } 1 \text { helicopter completely destroyed, } \\
\text { MV Samudra Suraksha sank }\end{array}$ \\
\hline Usumacinta jack up disaster & $\begin{array}{l}\text { Gulf of Mexico (off the } \\
2007 \text { coast of United States of } \\
\text { America) }\end{array}$ & Fires on oil rig, 22 lives lost \\
\hline $\begin{array}{l}\text { Collision between supply vessel MV Celeste } \\
\text { Ann }\end{array}$ & 2013 Gulf of Mexico & MV Celeste Ann sank \\
\hline Forties echo platform collision & 2015 North sea & Stopped production, 15 personnel evacuated \\
\hline
\end{tabular}

complex interactions between the captain and the vessel [4].

The past twenty years, numerous technological advancements have been achieved allowing the navigator to perform his job in a safer manner. The continuous improvement of safe practices, one path to catastrophe may be removed but new error opportunities and sequences to failure are introduced [5]. Table 1 explains several ship collisions with offshore installations.

Swift [6] lists two principal reasons as the main causes of collisions and groundings at sea-weaknesses in bridge organisation and the failure to keep a good lookout. This is based on the International Safety Conference INTASAFCON III which was held in Norway in 1975. Since then, there has been a dramatic increase in the field of offshore oil exploration. Over the past thirty years, exploration in the off shore sector has increased steadily.
Several organisations had begun in the early 1970's an effort to quantify the risks between ship-platform accidents. Technica was delegated, by the United Kingdom's DoE (Department of Energy), to carry out a study considering the evaluation of the risks collisions involving passing merchant vessels and off shore platforms on the UKCS (United Kingdom Continental Shelf) in 1981. A theoretical model was created from this study named CRASH and it was based on historical data and detailed survey of the UKCS shipping [7]. Following the CRASH's model other prevention collision models were developed as well from various organisations but without giving the desirable outcome, that of minimizing the accidents.

The existing rules and regulations of accidents prevention and hopefully, the results will be used from the respective companies and organizations that are dealing with collision risk analysis providing guidance to the navigators. In other words, the justification of 
this paper is to fill in the lack of knowledge and to contribute to the global governance by informing national and international policy makers with evidence-based data, analysis and a proposal as solution for a serious and growing safety and security problem at sea.

\section{Risk Assessment}

The working environment of an oil rig is extremely dangerous, which is surrounded by flammable and explosive gases. On board of the oil rigs are being implemented exceptionally high safety standards followed by preventive mechanisms like the blow out preventers. However, in the event of a collision, there is a fair probability of such safeties getting damaged. The collision accident of the M/V Samudra Suraksha and the MHN is an example of these probabilities, which led to multiple fires and explosions. Hence, the purpose of the safety on an oil rig is to reduce the risk of explosion that will lead to an incident or more so to an accident, but the impact of such a collision may eliminate the safeguard causing bigger problems to deal with.

This makes a risk assessment of an oil rig collision a necessity. Making a risk assessment for an oil rig collision is an extremely complexed procedure, much more than a general risk assessment of the daily oil rig's activities. Also risk assessments of such collisions should be carried out and from the vessel's side while sailing in to designated areas with oil rigs like the North Sea. As a senior ship manger explained that in an interview:

"Risk management is something seamen have always done. Seamen are very aware but seamen can be careless, tired and inexperienced. This business of formalising risks into checklists is a bit overdone. It is the caring supervision of ships operations by experienced DPA's actually sailing on the ships from time to time and having good internal audits that could overcome the navigational problems. The introduction of ECDIS will make this all more important. Risk assessment for a vigilant look out into these navigational waters must be implemented by the Company's SMS (Safety Management System) and must be carried out from the officers on board."

\section{The Role of the Human Factor in Prevention of S/O Collisions}

Most of the incidents at sea are caused by the factor of the human error, according to Swift [6]. Following the opinion of Swift, Rothblum et al. [8] explained that about $75-96 \%$ of the marine casualties are caused, at least partially, by some form of human error. She further reiterates that casualties' human error contributes to $89-96 \%$ of the collisions at sea and $84-88 \%$ of tanker accidents. The human error not only relates to any direct error made by a human being in control of decision making at the time of the accident, but also includes an error that may have led to it.

Human error is described as: an incorrect decision, an improperly performed action, or an improper lack of action (inaction). Thus, a lack of awareness of the position of a rig may also be accounted for as a human error, and the corrective action in this case would be to a train concerned so as to improve his/her awareness. An error on the part of the VTIS operator would also be categorised as human error. Invariably, addressing any human error issues involves training and retraining. Procedural or regulatory failure refers to collisions that are caused due to lack of procedure/regulation or insufficient procedure/regulation. There is inadequate research upon this in the maritime domain, especially with respect to oil rig collisions. This research has focused on this aspect.

\subsection{Root Causes of S/O Collisions}

Always when an oil rig collision occurs multiple causes exist. The Norwegian Petroleum Safety Authority PSA (2011) states that 26 collisions occurred between vessels and off shore platforms for the period of 2000-2010. Many of the causes were deficient organisation, inadequate training, lack of experience, 
failures of technical equipment. The Norwegian Petroleum Safety Authority PSA (2011) expresses the opinion that the following must be given more attention to prevent oil rig collisions [9]:

- Training;

- Organisational factors;

- Attempts to reduce the technical failure rate;

- Improvement in the quantification of the risk to collisions.

At the same time PSA does not acknowledge the need for a change in the regulations. This research attempts to study whether a change in regulations can prevent such oil rig collisions.

\subsection{The Co-relation between Human Error and Improved Procedures/Relations}

It may often be difficult to clearly distinguish between human error and procedural failure. Often, good procedures can prevent human errors. For example: an oil rig collision by a passing vessel may be ascribed to human error if the watch keeper did not alter course sufficiently. However, a procedure (the establishment of clear traffic lanes for navigation) would have completely eliminated such human error.

Thus, it can be argued that where human error has been identified as the cause of a collision, an improved procedure or regulation would be the appropriate preventive action. The DNV Loss causation model, used frequently in maritime accident investigation, also prescribes improved procedures as an effective preventive action. Such action always requires to be accompanied by dissemination of information. In the maritime sphere, this is largely carried out through training and education.

The UK Maritime Coastguard Agency states that, any attempt to address the human element must take human abilities, limitations and weaknesses into account. This is enumerated in the UK MCA's Human Element Strategy. The term "human element" itself refers to different human and organisational factors that affect the ship's crew, the shore based organisation, regulatory organisations, people involved in ship design and construction, charterers, insurers, trainers, shipyard workers and accident investigators [10].

In this way, even when introducing a new regulation or when improving/amending an existing regulation, it is important for us to keep this human element in consideration. One method by which this can be ensured by the use of the principles of good design when introducing a system of preventing oil rig collisions.

\subsection{Improvement of Procedures and Regulations}

The authors believe that good design can also, to a large extent address such errors. As an example it could be the establishment of a traffic lane in the vicinity of an oil rig which can prevent close quarters situations with that oil rig, as compared to an oil rig that has no traffic lanes near it. Such design would eliminate certain forms of error. Rothblum et al. [8] refer to the use of "human centred design". This design keeps the human operator topmost in mind when designing technologies, work environments and organisations, thus achieving three goals - supporting the human operator, fostering improved performance and minimising the risk of incidents and accidents [11, 12]. Such a design has been used also in other industries including those related to road development and transportation.

\subsection{Training as a Solution}

Naturally, such a solution will require building up awareness on the part of all personnel involved. A recommendation introduced in the vicinity of oil rigs is of little use if the mariners involved are not aware of it. This requires training and sometimes refresher training. As the UK's Secretary of State's Representative for Maritime Salvage and Intervention (SOSREP) shares the same opinion:

"The importance of the human factor is obviously the most crucial of them all. The proper navigation is up to the navigation officer carrying his lookout. The 
training that exists is sufficient for the mariners, but the frequency of the refreshing training isn't. Maybe we should focus also in the factor of the lack of rest due to the amount of work on board of a vessel. Perhaps additional navigation officers, may be plus one or two, to distribute the hours of navigation it would be all right."

\section{Conclusion}

The collision between a navigational ship and an oil rig may be something with a small probability, but as this paper has shown that it might be a quite often event eventually. Until today, there is not any major accident with catastrophic consequences reported but the consequence that will occur from such an incident must be taken into consideration. As far as the provisions required in respect of watch keeping and collision prevention regarding the off shore drilling platforms, same are very scattered and unspecified yet. Unfortunately, the difficulty to find a complete and integrated rule to set a specific standard for regulating the actions of offshore drilling platforms, is very high.

A first step would be to set up and carry out a proper statistic research, considering the likelihood of the accidents through an appropriate reporting system. Then, through the risk assessment process personnel from both sides (on board, shore staff) will be familiarized with possible incidents that may occur and the risk will be minimized, but not vanished.

The difficult part is to persuade all stakeholders that there is a need for the renewal of the COLREGs in all aspects, in order to include the offshore platforms/installations and not to fall into the same regulations concerning the navigational ships, as previously.

\section{References}

[1] Gault, S., Hazelwood, S. J., Tettenborn, A., and Plant, G. 2003. Marsden Collisions at Sea. London: Athenaeum
Press Ltd.

[2] Health and Safety Executive. 2006. "RR514: Overview of Collision Detection in the UKCS." Accessed March 21, 2016. Available http://www.hse.gov.uk/research/rrpdf/rr514.pdf.

[3] Bailey, D., Keith, C., and Tomlinson, P. 2015. New Perspectives on Industrial Policy for a Modern Britain. Oxford: Oxford University Press.

[4] BBC. 2015. "Offshore Supply Ship Manoeuvre and Crash 'Put Workers at Risk'." Accessed March 23, 2016. http://www.bbc.co.uk/news/uk-scotland-north-east-orkne y-shetland-33187807.

[5] Dekker, S. 2006. The Field Guide to Understanding Error. Hampshire: Ashgate Publishing Limited.

[6] Swift A. J. 2004. "Bridge Team Management, a Practical Guide, London in The Mariner's Handbook." Accessed March 20, 2016. Available at http://seagoinghk.org/ClassThree/Others/Mariners_Hand book.pdf.

[7] Hendrikse, J., McSweeney, K. P., Hoff, E. B., Atkinson, P., Miller, G., Conner, G., Poblete, B., Meyer, R., O’Connor, P., and Heber, H. 2002. "Application of Human Factors Engineering in Reducing Human Error in Existing Offshore Systems." In Proceedings of 2002 2nd International Workshop on Human Factors in Offshore Operations, Houston, Texas, April 8-11, 2002.

[8] Rothblum, A., Wheal, D., Withington, S., Shappell, Scott A., Wiegmann, Douglas, A., Boehm, W., and Chaderjian, M. 2002. "Improving Incident Investigation through Inclusion of Human Factors (HFW2002)." United States Department of Transportation-Publications \& Papers. Paper 32. Houston, TX, 1-6.

[9] Kvitrud, A. 2011, January. "Collisions between Platforms and Ships in Norway in the Period 2001-2010." In ASME 2011 30th International Conference on Ocean, Offshore and Arctic Engineering: 637-41. American Society of Mechanical Engineers.

[10] Hetherington, C., Flin, R., and Mearns, K. 2006. "Safety in Shipping: The Human Element." Journal of Safety Research 37 (4): 401-11.

[11] IACS. 2012. "A Guide to Risk Assessment in Ship Operations." Accessed March 23, 2016. Available at http://www.iacs.org.uk/document/public/Publications/Gui delines_and_recommendations/PDF/REC_127_pdf1842. pdf.

[12] Health and Safety Executive. 2003. "RR053: Ship/Platform Incident Database 2001." Accessed March 20, 2016. http://www.hse.gov.uk/research/rrpdf/rr053.pdf. 